\title{
A Guerra do Paraguai em perspectiva histórica
}

\author{
ENRIQUE AMATO
}

A GUERRA DO PARAgUaI ou da Tríplice Aliança não pode ser entendida fora do contexto mundial da época. Obviamente não é possível reconstruir todos e cada um dos elementos do passado. Temos de nos dar por satisfeitos com os fatos essenciais e universais que, como grandes linhas mestras, dão sentido e explicitam os fenômenos que o historiador, como cientista social, estuda num momento determinado.

Para os propósitos deste trabalho o contexto vai ser determinado pela revisão crítica do significado histórico da Pax Britannica, Free Trade (livre câmbio, livre comércio), e imperialismo.

\section{Pax Britannica}

O livro clássico de Imlah (1958) informa que Pax Britannica é a denominação do século transcorrido entre 1815, quando Napoleão é derrotado em Waterloo, e 1914, início da Primeira Guerra Mundial. Nesse período a Grã Bretanha, sendo a maior potência, impôs com habilidade as regras do jogo para manter a ordem mundial. Foi assim que nesse século, importante por. muitos fatos, destacou-se seu percurso relativamente pacífico, seguido de crescimento econômico. Na Europa, desde que apareceu o Estado-Nação, este foi o período mais longo de sua história sem guerras generalizadas. E verdade que nesse período da história européia aconteceram diversos conflitos locais, alguns até com a participação de grandes potências; mas foram curtos no tempo e pequenos na abrangência. Sempre de acordo com Imlah (1958), o mais parecido a uma guerra geral foi a da Criméia; mas não atingiu a escala das guerras que abriram e fecharam essa era e também não foi semelhante às que caracterizaram os quatro séculos precedentes. $\mathrm{O}$ crescimento econômico europeu foi extremamente rápido, impelido pelas novas forças incorporadas à produção através da máquina a vapor. $\mathrm{E}$ com isso cresceram também as aspiraçóes políticas dos novos setores sociais incorporados ao processo produtivo, entre eles o proletariado. Esses fatos não foram conseqüência de uma circunstância única ou do trabalho de uma naçáo apenas. Nesse sentido, Imlah informa que se as contribuiçóes da Grâ-Bretanha a essa era de paz e progresso foram importan- 
tes, ao ponto de conseguir-lhe o nome de Pax Britannica, não foi porque esse país tivesse tido a capacidade de impor a paz seguindo a forma romana, pela força policial. Mas porque a Grä-Bretanha foi capaz de, gradativamente, ir ao encontro do caminho que conduziu a políticas mais inteligentes, adaptadas a seus complexos interesses. Todo o poder militar da Grá-Bretanha foi usado para derrotar Napoleão e assim tornar possível o acerto pacífico que originou essa época. Desde então, esse poder desenvolveu seu papel na manutenção do equilíbrio nas relaçóes interestatais. Segundo Imlah, o que realmente distinguiu a Pax Britannica foi o poder de influência da Gră-Bretanha nas políticas de outros governos graças à sua admirada política liberal.

A Pax Britannica, que terminou definitivamente com a Primeira Guerra Mundial, foi declinando aos poucos através de várias décadas. Exemplo desse declínio foi o programa militar de Bismarck, executado na Prússia em 1862. O exército prussiano, surgido assim, entrou logo em açáo. As três curtas e vitoriosas guerras que travou não questionaram apenas o equilíbrio de poder e permitiram o aparecimento do Império Alemão, mas também outorgaram nova vida à noçáo de que a guerra poderia ser instrumento útil e de valor para a política nacional. Por isto, segundo Imlah (1958) desenvolveu-se na Europa a idéia de que não existiam plebiscitos para limitar ou validar as anexaçóes feitas pela força; o vitorioso era o soberano absoluto. Nos críticos anos 1860-70 a Grã-Bretanha não foi bem-sucedida na orientação do curso dos acontecimentos.

Ou seja que, com o passar do tempo, a Pax Britannica foi sendo questionada. Isto porque o treinamento militar, desde os anos 1860 , converteu-se na ordem do dia. No continente europeu, as potências desenvolveram grandes exércitos de conscritos que tinham o apoio de reservistas bem-treinados. Simultaneamente, reapareceram limitações ao comércio, junto aos esforços dos governos europeus de promover os interesses de seus nacionais no exterior e também de obter territórios no ultramar. Por esses territórios era preciso lutar e a GrãBretanha, na primeira linha, conseguiu áreas gigantescas. Foi assim que se desenvolveu novamente a competição para construir impérios. Então: "No meio desse reviver do nacionalismo econômico e do imperialismo, a Grã-Bretanha aderiu à sua política de free trade e continuou como o grande centro comercial do mundo... mas Londres năo foi mais o centro de gravitação diplomático... passou a ter um tipo de posição bipolar com Berlim... o prometedor concerto equilibrado entre as potências cedeu passo aos pactos de aliança e à competição pelo poder. A Europa e o mundo caminhavam para a primeira guerra geral do Século XX...” (Imlah, 1958:19).

Livros como o de Imlah definem a Pax Britannica como o período no qual a Europa, especificamente a Grá-Bretanha, era o centro do mundo; é definida como a imposição da paz através do diálogo e coordenação para manter o equilíbrio e resolver os problemas, essencialmente entre os Estados-Nação 
europeus. O fiel da balança era a Grã-Bretanha. Ou seja, Pax Britannica significa paz na Europa e, por extensão, nos países centrais; o que sucedia no resto do mundo, na chamada periferia, quase não conta na definição. Então a Pax Britannica, definida nesses termos, coincide claramente com uma visão eurocêntrica.

\section{Pax Britannica, grande depressão e imperialismo}

Durante a Pax Britannica houve uma crise de longa duraçáo (1873-96),conhecida como Grande Depressão, que determinou profundas mudanças não só na estrutura produtiva da Grä-Bretanha, como em toda a Europa. Chegou ao ponto de mudar a hierarquia de poder dos estados nacionais europeus e, portanto, do sistema capitalista em conjunto. Um importante pesquisador do Império Britânico disse: "Durante a Grande Depressão, a Grã Bretanha deixou de ser a fábrica do mundo, transformando-se $\mathrm{em}$ apenas. um dos três maiores poderes industriais e, em alguns aspectos essenciais, no mais fraco deles..." (Hobsbawn, 1969:104).

Considerando todo o sistema capitalista, a Grande Depressão foi um fenômeno que marcou o fim de uma fase e o início de outra, e não pode ser explicada apenas em termos britânicos, pois foi de desenvolvimento desigual. Ou seja, seus efeitos mudaram conforme o país; para alguns (como EUA, Alemanha e os recentemente chegados ao cenário industrial, isto é os países escandinavos), foi um período de grande avanço e não de estancamento. Então: "considerada em conjunto, a Grande Depressão marcou o fim de uma fase de desenvolvimento econômico - a primeira ou britanica da industrialização e o início da industrialização, fora da Grande Bretanha, das principais economias apanfadas $\mathrm{e}$, simultaneamente, a abertura das áreas de produção primária $\mathrm{e}$ agrícola até então não exploradas..." (Hobsbawn, 1969:104).

A Grande Depressão começou em 1873 principalmente pela falência da construção ferroviária (o setor industrial de ponta da época) e também porque numerosos países, na sua maioria da periferia, deixaram de pagar suas dívidas externas; os efeitos foram mundiais.

A Grã-Bretanha solucionou sua crise impulsionando o imperialismo. A falência iniciada em 1873 não foi temporal. De maneira diferente de outros países, que mudaram para o sistema de tarifas para proteger sua agricultura $\mathrm{e}$ indústria nacionais (França, Alemanha, EUA, entre outros), a Grä-Bretanha se fixou com firmeza no livre comércio. Comprometida totalmente com a tecnologia e organização empresarial da primeira fase da industrialização, não entrou com força nas novas tecnologias e no gerenciamento industrial impostos nos anos de 1890; "isso deixou a Grã Bretanha com uma única saída importante - tradicional para ela, mas que na época foi adotada também pelos outros competidores - a conquista econômica (e crescentemente política) das áreas do 
mundo ainda sem exploração. Em outras palavras, imperialismo" (Hobsbawn, 1969:107).

A crise global do sistema capitalista solucionou-se através de diversas formas de imperialismo. Formas como o imperialismo semiformal dos consórcios nacionais ou internacionais que se apropriavam do gerenciamento financeiro dos países fracos (Egito, Turquia, China etc.); ou o imperialismo informal dos investimentos externos (América Latina); ou, ainda, o imperialismo formal exemplificado pela Partilha da África; ou seja, a virtual divisão do mundo entre um grupo de potências da Europa ocidental, mais os Estados Unidos, nas últimas décadas do século XIX. Mas, "o imperialismo não foi novidade para a GrãBretanha. O novo foi o fim do virtual monopólio britânico do mundo subdesenvolvido e a consequiente necessidade de estabelecer formalmente, contra os competidores potenciais, regiōes de influência imperial...” (Hobsbawn, 1969:107).

Ao terminar a crise (1896), a Grä-Bretanha ainda continuava como a primeira potência mundial; mas já era apenas primo interpares. $\mathrm{E}$ o pesquisador britânico mencionado também informa que a Grande Depressão não foi uma fase do colapso do sistema capitalista; foi de reacomodamento, foi apenas um interlúdio (Hobsbawn 1976:307-8). Assim, a era imperialista, sob hegemonia britânica, solucionou o impasse com o crescente controle e exploração das áreas coloniais, neocoloniais e dependentes. Mas o processo trouxe mudanças: a Grã-Bretanha passou a compartir o nível de primeira potência com a Alemanha, a França e os EUA; com a Primeira Guerra Mundial o processo acelerouse, favorecendo o último dos países mencionados.

Depois do interlúdio, deu-se a franca explosão das contradiçóes no interior do fenômeno imperialista, explosão manifestada desde o início do Século $\mathrm{XX}$ através de guerras mundiais e movimentos revolucionários.

\section{Pax Britannica e exploração da periferia}

Desde a periferia, ou seja desde o ponto de vista não-eurocêntrico, a Pax Britannica, até com relação aos países centrais (especialmente europeus), foi um período de "paz". Assim, com minúsculas e aspas porque foi atingida por quatro guerras, além da de Criméia (1854-56). Foram as guerras da França, Sabóia e Itália contra Áustria (1858-59); Prússia e Áustria contra Dinamarca (1864); Prússia e Itália contra Áustria (1866) e os Estados Alemães contra a França (1870-71); e não apenas isso. Nos EUA, por cinco anos (1861-65), travou-se uma violenta guerra civil que, em termos de vidas humanas e destruição, foi "de longe, a maior guerra na qual participou, durante esse período, um país desenvolvido, ainda que empalidece relativamente se a compararmos com sua mais ou menos contemporânea Guerra do Paraguai... e fica totalmen- 
te superada comparada com a Revolução Taiping da China (1850-56)" (Hobsbawn, 1976:142).

Ou seja, desde a ótica não-eurocêntrica, se a Pax Britannica para a Europa (e os países centrais) significou $p a z$, para a periferia normalmente foi sinônimo de guerra. E a mais suja, abusiva e injusta das guerras pois em quase todos os casos enfrentaram-se oponentes muito desiguais. Num lado estavam os chefes, geralmente conservadores, dirigindo seus povos armados principalmente com moral, ou seja, com a vontade de não serem conquistados; além disso tinham poucos recursos materiais pois suas armas eram pedras, paus, flechas, lanças, espadas, fuzis de pederneira e, às vezes, pequenos canhões. Do outro lado se encontravam geralmente tropas profissionais, muito bem-treinadas e armadas com os maiores avanços da revolução industrial aplicados à produção militar: canhōes de grande calibre, fuzis de repetição; metralhadoras, canhoneiras etc. É bom lembrar, por exemplo, que o grande sucesso militar de Kirtchetner na conquista do Sudão foi devido a que os soldados ingleses, com metralhadoras, lutaram com um povo armada principalmente de lanças. Apenas isso explica porquê, nas cinco horas de batalha de Ombdurman, em 2 de setembro de 1898, onze mil sudaneses foram mortos contra 386 homens de Kirtchetner (Robinson \& Gallagher, 1969:369).

O significado real da Pax Britannica para a periferia far-se-á evidente com a análise de algumas agressões notórias. Agressões feitas pelos países centrais, especialmente europeus (com a Grã-Bretanha geralmente em posição de destaque) contra diversas regióes da periferia. Não se pode fazer aqui essa análise e, portanto, apenas serão mencionadas algumas da mais famosas. Por exemplo, as duas Guerra do Ópio (agressões da Grã-Bretanha para abrir o mercado da China, 1839-42 e 1856-60); as violentas repressōes ao chamado Motim Índio (Grã-Bretanha contra o emergente nacionalismo da Índia, 185758), ou à Rebelião Argelina (França contra um fenômeno similar ao anterior, mas na Argélia, 1871); a Partilha da Africa (entre 1880 e fins desse século, as grandes potências européias, com Grã-Bretanha na frente, "lutaram para se apropriar de nove décimos do continente africano", Robinson \& Gallagher, 1969:39).

E também ter-se-ia de dizer que, em outras partes da periferia, as potências européias assinaram acordos para recuperar suas colônias. Sob a proteção da Convenção de Londres, ou Tripartite (assinada pela Grã-Bretanha, França e Espanha), viabilizou-se o plano para que essas potências tentassem recolonizar a América Hispana. Ali se encontra, por exemplo, o alicerce da agressão que especialmente a França e a Grã-Bretanha desenvolveram contra o México (1861-67). Alicerce também da intentona da Espanha para recuperar suas colônias da América do Sul através da agressão principalmente ao Peru (1863-66). 


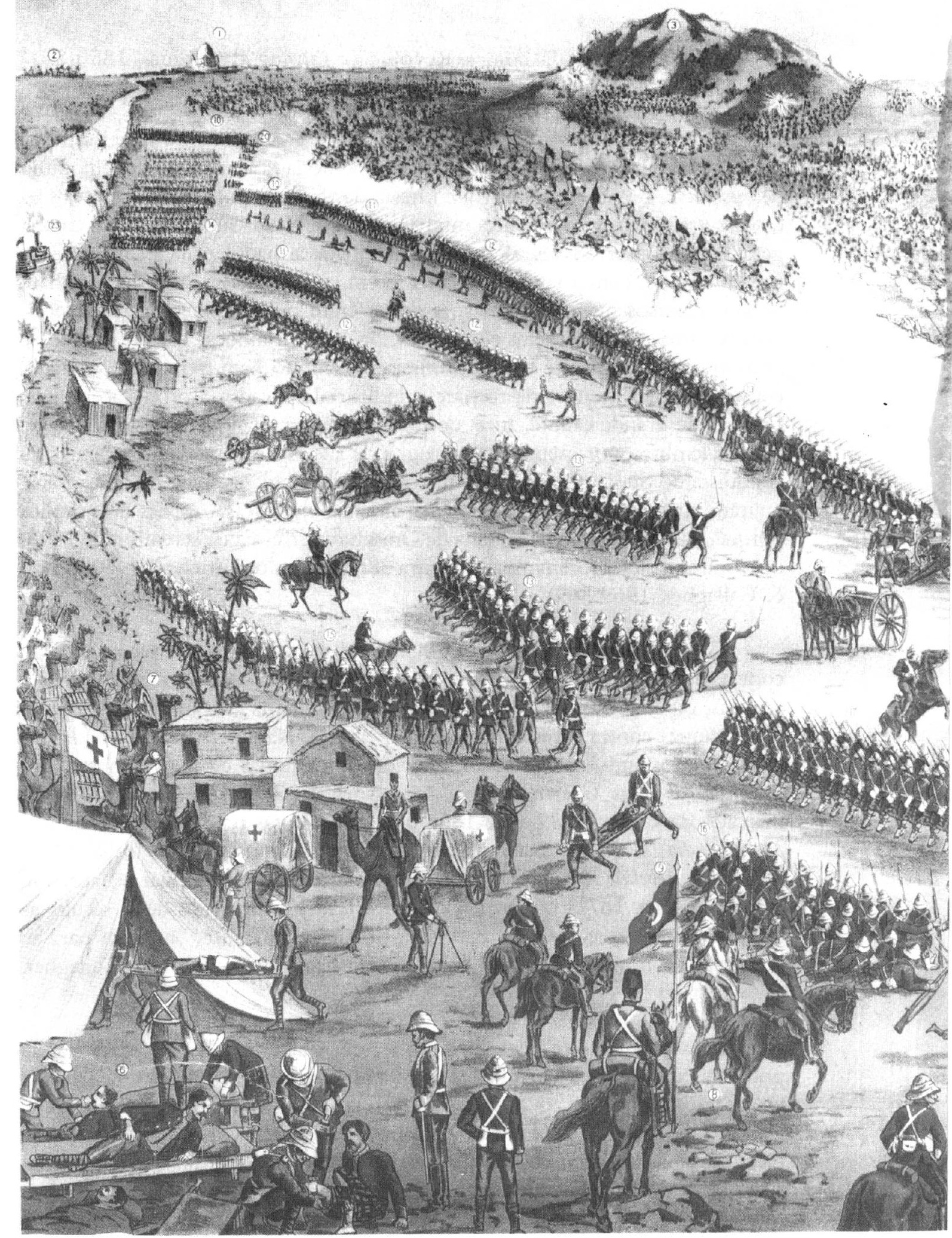




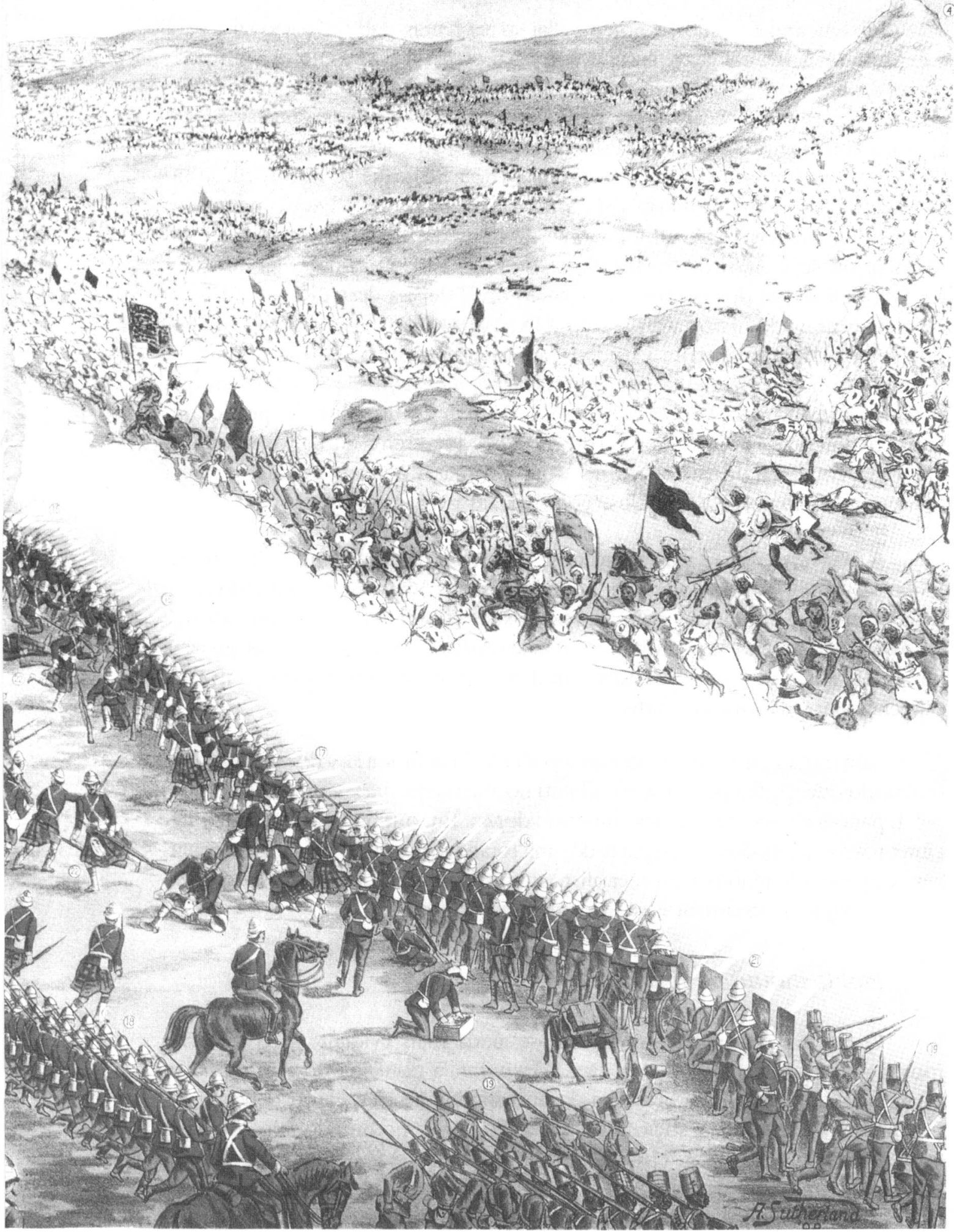

A batalha de Ombduman (1898), descrita pelo artista A. Sutherland, ilustra a desigualdade entre os contendedores: de um lado, tropas ordenadas e limpas, com fuzis, canhöes e canboneiras; de outro, soldados desorganizados, armados com espingardas, espadas e lanģas. Foi o seguinte o saldo da batalha: morreram 11 mil sudaneses contra 386 ingleses. 
Igualmente, teríamos de mencionar as violentas guerras nacionais, para a expansão das fronteiras, realizadas entre países periféricos ou entre um periférico e um central. Em todos esses casos os resultados beneficiaram especialmente os países centrais. As mais representativas dessas guerras se deram no continente americano. Por duas vezes o México foi agredido pelos EUA; a primeira foi a Guerra pelo Texas (1835-36), que se transformou no alicerce da segunda, a Guerra pela Califórnia (1845-48). Dessa maneira o expansionismo dos EUA tomou posse de mais da metade do território do México, ou seja, mais de dois milhões de $\mathrm{km}^{2}$. Em outra área, na América do Sul, deu-se um dos conflitos que, pelo nível de sua destruição, está entre os mais brutais da história do século XIX. Foi a Guerra do Paraguai (186470), que será rapidamente estudada adiante. A América do Sul também testemunhou outra violenta luta. Foi a Guerra do Pacifico (1879-83) em que o Chile enfrentou o Peru e também a Bolívia (estes últimos perderam, respectivamente, $180 \mathrm{mil} \mathrm{km}^{2}$ e 100 mil km $\mathrm{km}^{2}$ que eram, então, os de maior valor na América do Sul). Nestas duas últimas guerras, a Grä-Bretanha conseguiu os maiores benefícios, como ficará evidente posteriormente.

A abertura violenta de mercados, a partilha de um continente (novamente a violência para converter povos atrasados, mas livres, em colônias), os acordos entre potências para recuperar suas colônias, a repressão (através de banhos de sangue) dos movimentos nacionalistas emergentes e as guerras na periferia, tudo isso foi funcional à expansão dos países centrais, especialmente da Grã-Bretanha.

Com uma visão não-eurocêntrica poder-se-ia definir a Pax Britannica como o período que, para a periferia, significou normalmente guerra injusta e de opressão. E para os países centrais, foi sinônimo de paz. Em outras palavras, os acontecimentos mencionados foram parte de uma totalidade maior e única: a emergência e expansão do fenômeno imperialista em nível mundial. Apenas nesse contexto é que esses acontecimentos se tornam compreensíveis.

\section{Pax Britannica e Free Trade}

O que foi dito anteriormente faz-se ainda mais evidente se considerarmos o seguinte. No período da Pax Britannica, a doutrina do free trade foi aceita pela classe dirigente britânica e transformada no elemento essencial para organizar sua economia e sociedade e para projetar-se no mundo. No ambiente criado pela Pax Britannica, cresceu o free trade e sua expansão em nível mundial justificou a tendência a eliminar as barreiras que o limitavam, fossem elas tarifas ou monopólios de Estados fracos e/ou isolacionismo ou tribos ou naçóes etc. Nesse processo, a força milițar foi usada à vontade, sempre que preciso. Mas realmente importante para a Grä-Bretanha foi finalmente obter um 
tratado diplomático, assinado com o país desejado, para abrir o mercado deste último em termos de igualdade (assim acabaram as Guerras do opio). Durante a Pax Britannica, o free trade foi imposto ao mundo e, nesse processo, fizeram-se necessários mercados como os da América Latina: grandes e quase sem competidores. A abertura deles, num período chave, foi essencial para a realização da produção industrial, principalmente da Grã-Bretanha (Hobsbawn, 1971:98).

\section{Pax Britannica e América Latina}

Na América Latina, a Pax Britannica manifestou-se como no resto da periferia, ou seja, através da agressão que beneficiou primeiro a Grã-Bretanha e depois os outros países centrais. As formas de agressão na América Latina corresponderam normalmente a dois tipos: formais e informais.

As primeiras são fáceis de reconhecer pois as potências agressoras, em determinado momento, ou assinaram um tratado vinculado diretamente à agressáo ou o Estado agressor a realizou com o apoio de seus poderes (Executivo e/ou Legislativo) ou fez uma declaração de guerra. É o caso, por exemplo, das já mencionadas intervenções armadas contra o Peru e o México resultantes da Convenção de Londres; nessa convenção a Grã-Bretanha foi o eixo. E também são agressóes formais as dos EUA contra o México (já mencionadas) e contra a Espanha pela posse de Cuba, Porto Rico e Filipinas (1898).

Mas também existem as agressões informais. As de tal tipo estão relacionadas diretamente com este trabalho, pois seus casos mais representativos são a Guerra do Paraguai e a Guerra do Pacífico. E são informais porque, por parte das potências centrais, ou não existe qualquer tipo de tratado ligado diretamente à agressão ou seus poderes não a apoiaram. Nesses casos as mencionadas potências, especialmente a Grã-Bretanha, afirmavam que não praticaram qualquer agressão e oficialmente reconheceram apenas sua neutralidade. Negam sua participação e quando conseguem reconhecer que alguns de seus súditos ou empresas obtiveram grandes benefícios nessas guerras, simultaneamente afirmam que seus governos nunca se beneficiaram e jamais abandonaram a neutralidade. Ou seja, não reconhecem ter tomado partido a favor de um dos contendores.

Mas a agressão foi uma realidade que pode ser detectada através de dois efeitos, inter-relacionados, produzidos nas sociedades que a sofreram. O primeiro é o maior empobrecimento e fraqueza dos contendores. Até mesmo os vitoriosos, no melhor dos casos, depois de um enriquecimento de curto prazo têm também de enfrentar a pobreza a médio prazo; quanto aos perdedores, seu futuro normal é enfrentar a destruição e a ruína. O segundo efeito é que enriquece e aumenta ainda mais a hegemonia dos países centrais; o grau de hegemonia destes países sobre os contendores dependerá de seu nível de parti- 
cipação na agressão. Para os contendores, sua maior ou menor dependência estará relacionada diretamente ao fato de ter sido ganhador ou perdedor e, indiretamente, ao grau de problemas de sua economia e sociedade após a guerra.

Como não existem, por parte dos países centrais, tratados ou apoio expresso de seus poderes ligando-os a este tipo de agressão, só estudos aprofundados provarão que a economia desses países beneficiou-se com tais conflitos. E não apenas isso, pois esse tipo de estudos também provará que a declarada neutralidade oficial dos governos centrais foi, normalmente, só neutralidade; ou seja, de maneira sutil mas efetiva, tomaram partido. $\mathrm{Na}$ agressão informal, no período em estudo, a Grã Bretanha desenvolveu um papel de destaque; isto fica demonstrado pelo fato de ter sido ela a que conseguiu os maiores benefícios.

\section{A Guerra do Paraguai}

É conhecida também com o nome de Guerra da Tríplice Aliança (186470), porque confrontou os aliados Argentina, Brasil e Uruguai contra o Paraguai. A partir do exposto anteriormente poder-se-ia dizer que ela é apenas parte de um conjunto de guerras que caracterizam a emergência e desenvolvimento da fase imperialista. Faz parte das agressóes que a periferia sofreu das potências centrais nesse período. Agora, deve-se esclarecer que não cabe a este trabalho fazer uma análise aprofundada dessa guerra. Seu objetivo é apenas contribuir para provar que a Grá-Bretanha lucrou muito e nấo ficou neutra. Isto será feito observando-se rapidamente alguns dados econômicos dos países sul-americanos participantes nessa guerra e o caráter da política desenvolvida pela GrãBretanha.

\section{Alguns dados económicos}

Anotemos de início que o Paraguai, antes da guerra, tinha sido um caso único na América Latina. Seu modelo econômico era a procura do desenvolvimento autônomo a partir de suas próprias forças. Por isso tinha praticado o isolamento e fechado seu mercado ao exterior. Em função desse procedimento, por exemplo, não havia solicitado qualquer empréstimo ao exterior. Mas isso mudou radicalmente como conseqüência da guerra, ao ponto em que finalmente: "residentes da Grã-Bretanha fizeram seu primeiro grande investimento no Paraguai [imediatamente após a guerra] nos anos $1871 \mathrm{e}$ 1872, comprando duas emissóes do Governo paraguaio por um total de 1.505.400 libras esterlinas...” (Rippy, 1959:124). 
Enquanto isso os países aliados, todos de economia aberta, estavam já endividados desde antes da guerra. E, para poder sustentar seus gastos de guerra, tiveram que aumentar ainda mais o ritmo dos empréstimos. Os bancos ingleses, principalmente através de The Baring Brothers e The Rotschild Bank, fizeram empréstimos de forma permanente. Depois do conflito, a dívida dos vencedores foi maior que nunca. Os dados a seguir quase não precisam de comentários.

O Uruguai tinha feito um empréstimo que em 1864 chegava a um mithão de libras esterlinas. Assim que terminou a guerra, em 1871, negociou o segundo, por 3.500.000 libras esterlinas (Rippy, 1959:142). A Argentina, até 1864 , continuava acumulando seu primeiro empréstimo feito em 1824, no valor de um milhão de libras esterlinas. Mas a partir de 1865 (segundo ano do conflito com o Paraguai) e até 1876, negociou oito empréstimos em um total de 18.747.884 libras esterlinas (Pomer, 1968:357). O Brasil, entre 1824 e 1865, tinha acumulado empréstimos num montante de 18.138.120 libras esterlinas; desse total apenas o de 1865 foi de um terço, ou seja, de 6.363.613. Depois da guerra, em 1871, negociou um empréstimo de três milhôes de libras esterlinas; em 1875, outro no valor de 5.301.200. Posteriormente, entre 1883 e 1889, endividou-se com mais quatro empréstimos num total de 37.202.900 libras esterlinas. Isso que diżer que em 18 anos (de 1871 a 1889), o Brasil conseguiu empréstimos de 45.500 .000 libras esterlinas, ou seja, quase duas vezes e meia a mais que nos 47 anos precedentes (Pomer, 1968:83 e 355). Foi essa uma das maneiras como o capital participou nessa guerra. Através desses empréstimos, britânicos especialmente, foi possível, em grande parte, manter os exércitos aliados. Simultaneamente, ao Paraguai se negou a possibilidade de conseguir qualquer empréstimo, apesar desse país ter enviado agentes especiais para obtêlo no Mercado Monetário de Londres (Fornos Peñalba, 1979:116-117).

\section{A politica britanica}

A política da Grã-Bretanha não é clara nessa guerra. Oficialmente foi neutra (Smith, 1969:226). Mas na verdade, a política da Grã-Bretanha foi neutra. Por exemplo, é conhecido que o ministro britânico em Buenos Aires, Edward Thornton, participou ativamente no conflito a ponto de ter sido assessor do Governo da Argentina. Foi tanta a sua importância, que participava das reunióes do Gabinete da República Argentina, onde se decidia o curso da guerra. Ali se sentava, como símbolo de confiança, junto ao presidente Mitre. Em outras palavras, o ouvido do presidente ficava totalmente a seu alcance. Além disso, participou ativamente do processo de organização do acordo de aliança entre Argentina e Brasil contra o Paraguai (Galeano, 1973:210; Trías, 1975:18). Evidentemente, Thornton năo teria assim atuado sem o apoio, pelo menos implícito, do Foreign Office britânico (Pomer, 1968:68). 
O nicaraguense Fornos Peñalba, em sua tese de doutorado The fourth ally. Great Britain and the War of The Triple Alliance, apresentada à Universidade da Califórnia, documenta bem a política britânica nessa guerra. $\mathrm{E}$ demonstra que não apenas Thornton, mas a política britânica conjunta, trabalhiou contra o Paraguai. O país, mediterrâneo, considerava vital o livre acesso ao mar através do Uruguai. Mas a Grã-Bretanha não admitiu que a possível absorção da República do Uruguai pela Argentina ou pelo Brasil afetaria materialmente a vida do Paraguai, ou que seria uma ameaça à livre navegação pelo sistema de rios compartido por esses quatro países sul-americanos. Fornos Peñalba usa numerosas fontes primárias para provar suas afirmações e, nas suas conclusóes, diz: "A Grã Bretanha facilitou em muito o entendimento e aliança entre Buenos Aires e Rio de Janeiro. E essa aliança foi a chave para apoiar Venancio Flores [presidente do Uruguai, 1865-68] até que Montevidéu fosse controlada por ele e para a subsequente destruiçáo do Paraguai. A Grã Bretanha, em todas as etapas da mediação entre Brasil, Flores e Buenos Aires, atuou nas sombras, dando assistência e apoiando os dois rivais tradicionais transformados em aliados. A Grã Bretanha apoiou o Brasil e Buenos Aires, primeiro contra o Uruguai e depois contra o Paraguai”' (Fornos Peñalba, 1979:194).

Os resultados são conhecidos. O Paraguai foi quase que totalmente destruido mas, finalmente, foi aberto ao free trade. Então, os beneficiados foram, primeiro, os interesses britânicos; estes, finalmente, conseguiram entrar no Paraguai e, simultaneamente, conseguiram também aumentar seu controle econômico sobre os vitoriosos. Em segundo lugar, podemos citar os governos argentino e brasileiro; estes, além de obterem grande parte do território paraguaio, deixaram de temer seu modelo que, como dissemos, antes da guerra era não-escravocrata, isolado e poderoso. $O$ Uruguai de Flores foi o aliado menor, que nada conseguiu (Galeano, 1973:212).

Aqui importa destacar, como foi feito pelo ministro da Fazenda da Argentina, que a guerra foi de especial importância para a Grá-Bretanha pois trouxe grandes vantagens para o seu comércio. "No ponto relacionado com seus próprios interesses, a Grã Bretanha, longe de estar preocupada com a guerra, aguarda com ansiedade o final dela, não pelos seus males, mas porque espera lançar sua utilitária especulação sobre o Paraguai, fechado até agora a seus benefícios" (Memória. Ministro de Estado. Gonzales a Norberto de la Riestra. Confidencial. Buenos Aires. 28.3.1867; in Fornos Peñalba, 1979:199).

Nas açóes contra o Paraguai coincidiam os interesses britânicos, argentinos e brasileiros; foi isso o que selou uma aliança informal. A agressão informal, que também caracteriza a Pax Britannica na periferia latino-americana, trabalhava através desse tipo de alianças. Ou seja, é a aliança de interesses (por coincidência deles) o que caracteriza a agressão informal. Isto é ainda mais evi- 
dente quando se estuda a política britânica na Guerra do Pacífico, o que é feito aprofundadamente no meu livro citado no início deste trabalho.

\section{Conclusão}

Do anterior, pode-se deduzir que a Guerra da Tríplice Aliança trouxe grandes benefícios para a Grã-Bretanha. E não apenas do derrotado Paraguai, mas também dos vitoriosos Argentina, Brasil e Uruguai. É claro também que essa guerra foi parte de um conjunto de guerras que caracterizam a emergência e o desenvolvimento do fenômeno imperialista sob hegemonia britânica.

Igualmente, pode-se deduzir que a Pax Britannica não significou paz, mas a manutenção de uma ordem mundial em favor, primeiro e especificamente, da Grä-Bretanha e a seguir dos países centrais. Em outras palavras: de uma ordem mundial em favor dos interesses da burguesia britânica, européia e dos países centrais em geral; isso, em detrimento de seu proletariado e de outras classes subalternas, além dos países periféricos em geral. Estes últimos, por agressão direta e/ou domínio econômico, foram transformados em colônias, semi-colônias ou países dependentes.

Referências bibliográficas

FORNOS PENAALBA, J. The fourth ally: Great Britain and the War of the Triple Alliance. Ph.D. tese. Los Angeles, Universidade de California, 1979.

GALEANO, E. Open veins of Latin America. New York, Monthly Review Press, 1973.

HOBSBAWN, E.J. The age of capital, 1848-1875. Londres, Weidenfeld \& Nicolson, 1976. . El impacto de la Revolución Industrial 1789-1848. In: La Indenpendencia del

Peru. Lima, Instituto de Estudios Peruanos, 1971. . Industry and empire. Londres, Weidenfeld \& Nicolson, 1969.

IMLAH, A. Economic elements in the Pax Britannica. Cambridge, Harvard University Press, 1958.

POMER, L. La Guerra del Paraguay. Gran negocio!. Buenos Aires, Calden, 1968.

RUPPY, F. British investments in Latin America. Minneapolis, University of Minnesota Press, 1959. 
ROBINSON, R. \& GALLAGLER, J. Africa and the victorians. The official mind of imperialism. Londres, McMillan e Co. Ltd., 1965.

SMITH, J. Illusions of conflict. Anglo-American diplomacy toward Latin America, 1865-1896. Pittsburgh, University of Pittsburgh Press, 1979.

TRIAS, V. De Francia el supremo a la Guerra de la Triple Alianza. Buenos Aires, Cuadernos de Crisis n. 19, 1975.

\section{Resumo}

A Guerra do Paraguai ou da Tríplice Aliança não pode ser entendida fora do contexto mundial da época. Obviamente, não é possível reconstruir todos e cada um dos elementos desse passado. Temos de nos dar por satisfeitos com os fatos essenciais e universais que, como grandes linhas mestras, dão sentido e explicitam os fenômenos que o historiador, como cientista social, estuda num momento determinado. Para os propósitos deste trabalho, o contexto vai ser determinado pela revisão crítica do significado histórico da Pax Britannica, Free Trade (livre câmbio, livre comércio) e imperialismo, sob hegemonia da Inglaterra.

\section{Abstract}

The Paraguayan War or The War of the Triple Alliance can not be properly understood outside the world context of its time. It is obvious that it is not possible to reconstruct each and every element from the past and, since it is impossible to do so, it makes not sense to try. The world context, however, it is crucial and has to be reconstructed, at last, in its main and universal elements. Those will be the frame for the phenomena that the historian, as social scientist, studies in a given moment. For the purposes of the present work the context will be determined by a critical review of the historical meaning of Pax Britannica, Free Trade and imperialism under England's hegemony.

Enrique Amayo, peruano, é professor da área de História Econômica do Departamento de Economia da Universidade Estadual Paulista (Unesp), onde também exerce o cargo de assessor da vice-reitoria. Foi professor visitante do IEA-USP nos anos de 1990 e 1991.

Este texto é um resumo do capítulo II do livro do autor La politica britanica en la Guerra del Pacifico, 1876-1891.Lima, Editorial Horizonte, pp xxi + 288. Foi apresentado no colóquio Guerra do Paraguai - 130 anos depois, realizado em 24 de novembro de 1994, no Rio de Janeiro. O evento foi promovido pela Biblioteca Nacional, com o apoio da Fundação Roberto Marinho e do Banco Real.

O autor agradece ao professor Carlos Guilherme Mota pela organização do Colóquio e a Sandra Agulhare pela transcrição deste texto. 